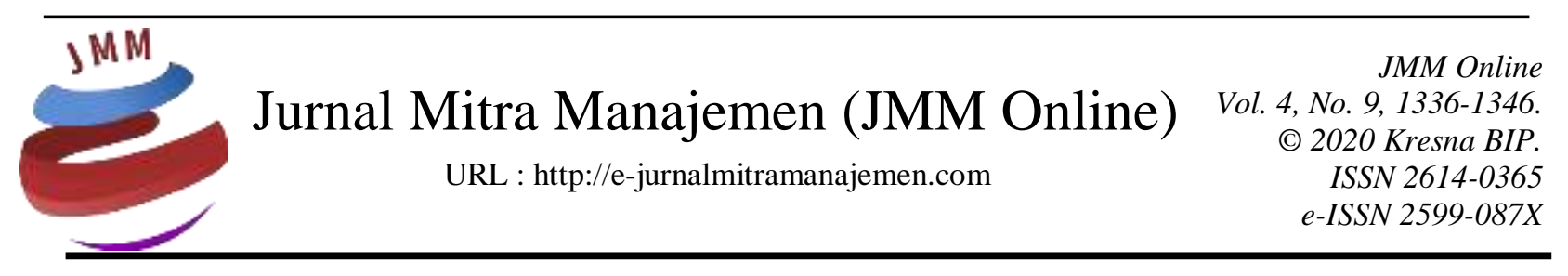

\title{
PENGARUH WORK-FAMILY CONFLICT DAN STRES KERJA TERHADAP KINERJA KARYAWAN WANITA DI RS MEDIKA DRAMAGA BOGOR
}

\author{
Feby Cahya Sapitri ${ }^{1)}$, Nidya Dudija ${ }^{2)}$ \\ Universitas Telkom
}

INFORMASI ARTIKEL

Dikirim : 07 September 2020

Revisi pertama : 08 September 2020

Diterima : 14 September 2020

Tersedia online : 01 Oktober 2020

Kata Kunci: Work-Family Conflict, Stress Kerja, Kinerja Karyawan

Email :

febycahyasapitri@student.telkomuniversity.ac.id ${ }^{1)}$, nidyadudija@telkomuniversity.ac.id ${ }^{2)}$

\section{ABSTRAK}

Tujuan penelitian ini adalah untuk untuk melihat bagaimana tingkat work-family conflict, tingkat stres kerja dan tingkat kinerja karyawan dalam perusahaan dan bagaimana pengaruh work-family conflict dan stres kerja terhadap kinerja karyawan di RS Medika Dramaga Bogor. Metode penelitian menggunakan metode penelitian kuantitatif. Metode pengumpulan data pada penelitian ini diperoleh dengan menggunakan penyebaran kuesioner pada 112 responden.

Hasil yang diperoleh dari penelitian ini adalah terdapat pengaruh signifikan antara WorkFamily Conflict dan Stres Kerja terhadap Kinerja Karyawan Wanita. Artinya apabila work-family conflict meningkat dan stres kerja meningkat maka kinerja karyawan yang dihasilkan akan menurun.

Koefisien determinasi yang didapat pada penelitian ini menunjukkan nilai $R$ square sebesar 0.748. Artinya ada pengaruh antara variabel WorkFamily Conflict dan Stres Kerja terhadap Kinerja Karyawan Wanita sebesar $74.8 \%$ sedangkan sisanya $25.2 \%$ merupkan pengaruh variabel-variabel lain yang tidak peneliti libatkan dalam penelitian ini. Hasil penelitian ini akan menjadi masukan bagi RS Medika Dramaga untuk selalu mengelola tingkat work-family conflict dan stres yang bisa dialami suatu saat oleh karyawan yang dapat menurunkan kinerja karyawan pada masing-masing karyawan dalam organisasi dengan selalu memperhatikan kesejahteraan karyawan. 


\section{PENDAHULUAN}

\section{Latar Belakang}

Berdasarkan hasil Sensus Penduduk 2010, jumlah angkatan kerja adalah 107,7 juta jiwa. Dari jumlah tersebut, jumlah penduduk yang bekerja adalah 104,9 juta jiwa, terdiri dari 66,8 juta orang laki-laki dan 38,1 juta orang perempuan (informasi tematik sensus penduduk 2010 badan pusat statistik). Seiring dengan perkembangan zaman, fenomena wanita bekerja merupakan suatu hal yang biasa. Kita telah mengetahui bahwa saat ini penempatan posisi wanita pada level yang sejajar dengan pria, terutama dalam masalah ketenagakerjaan (informasi tematik sensus penduduk 2010 badan pusat statistik). Hal tersebut bisa menyebabkan terjadinya terjadinya work-family conflict didalam suatu pekerjaan (Retnaningrum et al., 2016). Dimana terjadi peran ganda yang dimiliki oleh suatu karyawan yatu perannya dalam perusahaan dan perannya dalam keluarga. Tuntutan sebagai suami atau istri yang keduanya bekerja akan meningkatkan hubungan ketergantungan antara pekerjaan dan keluarga. Kondisi ini akan menciptakan terjadinya konflik antara tuntutan pekerjaan dan keluarga atau yang disebut work-family conflict (WFC). Peran ganda yang dimiliki menuntut seseorang untuk dapat seimbang dalam melakukan pekerjaan paran yang satu dengan yang lain termasuk pekerjaan dalam perusahaan dan keluarga. (Sugiyanto et al. ,2016).

Semakin banyak peran yang dimiliki oleh seseorang maka semakin banyak pula tanggung jawab dan pekerjaan yang harus dilakukan. Semakin banyak tuntutan kerja dan tanggung jawab terhadap karyawan tersebut maka akan semakin tinggi pula tingkat stres yang dialami keryawan tersebut. Akan tetapi tidak hanya itu saja yang ditimbulkan oleh konflik yang tidak ditangani secara tepat dan bijaksana, dapat pula berakibat langsung pada diri karyawan, karena mereka dalam keadaan suasana serba salah sehingga mengalami tekanan jiwa (stress) (Tjokro et al., 2015). Stres adalah suatu kondisi ketegangan yang mempengaruhi emosi, proses berpikir dan kondisi seseorang. Stres yang terlalu besar dapat mengancam kemampuan seseorang untuk menghadapi lingkungan. Sebagai hasilnya, pada diri para karyawan berkembang berbagai macam gejala stres yang dapat mengganggu pelaksanaan kerja mereka.Untuk itu salah satu dalam meningkatkan kualitas kerja karyawan adalah mengelola tingkat stres dan menghilangkan tekanan pekerjaan pada karyawan (Handoko, 2014:200)

Di era industrialisasi ini, rumah sakit merupakan organisasi yang bergerak sarana penyedia layanan kesehatan untuk masyarakat. Rumah sakit sebagai institusi penyedia jasa pelayanan kesehatan perorangan secara paripurna memiliki peran yang sangat strategis untuk mewujudkan derajat kesehatan yang setinggi- tingginya (Undang-Undang Republik Indonesia No. 44 Tahun 2009; Departemen Kesehatan Republik Indonesia [DEPKES RI] 2009). Rumah sakit dituntut untuk memberikan pelayanan yang bermutu sesuai dengan standar yang ditetapkan dan dapat menjangkau seluruh lapisan masyarakat (Keputusan Menteri Kesehatan No. 129 Tahun 2008). Dalam pelayanannya, rumah sakit diharuskan untuk memberikan pelayanan yang baik bagi masyarakat karena menyangkut kesehatan serta kepentingan bagi orang banyak. Dalam memberikan layanan yang terbaik kepada masyarakat, tentunya tidak terlepas dari kinerja para karyawan didalamnya. Karyawan rumah sakit merupakan tenaga profesional yang perannya tidak dapat dikesampingkan dari semua bentuk pelayanan 
rumah sakit. Peran ini disebabkan karena tugas perawat mengharuskan kontak paling lama dengan pasien

\section{Rumusan Masalah}

Berdasarkan latar belakang diatas, maka rumusan masalah dalam penelitian ini adalah sebagai berikut.

1. Bagaimana pengaruh work-family conflict terhadap kinerja karyawan RS Medika Dramaga?

2. Bagaimana pengaruh stres kerja terhadap kinerja karyawan RS Medika Dramaga?

3. Bagaimana pengaruh work-family conflict dan stres kerja terhadap kinerja karyawan di RS Medika Dramaga?

\section{Tujuan Penelitian}

Berdasarkan rumusan masalah diatas, maka tujuan dalam penelitian ini adalah sebagai berikut.

1. Mengetahui pengaruh work-family conflict terhadap kinerja karyawan RS Medika Dramaga

2. Mengetahui pengaruh stres kerja terhadap kinerja karyawan RS Medika Dramaga

3. Mengetahui pengaruh work-family conflict dan stres kerja terhadap kinerja karyawan RS Medika Dramaga

\section{KAJIAN PUSTAKA \\ Work-Family Conflict}

Work-family conflict atau konflik pekerjaan keluarga adalah konflik peran yang terjadi pada karyawan, di satu sisi ia harus melakukan pekerjaan di kantor dan di sisi lain harus memperhatikan keluarga secara utuh, sehingga sulit membedakan antara pekerjaan mengganggu keluarga dan keluarga mengganggu pekerjaan. Pekerjaan mengganggu keluarga, artinya sebagian besar waktu dan perhatian dicurahkan untuk melakukan pekerjaan sehingga kurang mempunyai waktu untuk keluarga. Sebaliknya keluarga mengganggu pekerjaan berarti sebagian besar waktu dan perhatiannya digunakan untuk menyelesaikan urusan keluarga sehingga mengganggu pekerjaan (Korabik et al., 2017:174) Wanita karier memiliki beban ganda sebagai wanita yang bekerja diluar rumah dan juga didalam rumah. Apabila hal ini tidak ditunjang dukungan keluarga, maka bisa saja menimbulkan konfil pekerjaan keluarga (workfamily conflict) dan mengganggu pemenuhan lainnya dan berakibat dengan prestasi kerja (Setiyanto, 2017: 118). Alat ukur work-family conflict yaitu Time-Based Conflict (konflik berdasarkan waktu). Konflik berdasarkan waktu merupakan konflik yang terjadi karena waktu yang digunakan untuk memenuhi satu peran tidak dapat digunakan untuk memenuhi peran lainnya, meliputi pembagian waktu, energi dan kesempatan antara peran pekerjaan dan rumah tangga. Strain Based Conflict (konflik berdasarkan tekanan). Konflik berdasarkan tekanan mengacu kepada munculnya ketegangan atau keadaan emosional yang dihasilkan oleh salah satu peran membuat seseorang sulit untuk memenuhi tuntutan perannya yang lain Behavior Based Conflict (konflik berdasarkan perilaku) Konflik berdasarkan perilaku yaitu konflik yang muncul 
ketika pengharapan dari suatu perilaku yang berbeda dengan pengharapan dari perilaku peran lainnya (Korabik et al., 2017:174).

\section{Stres Kerja}

Stres kerja merupakan sesuatu yang dianggap negatif dan biasanya disebabkan oleh sesuatu yang buruk dalam menyesuaikan diri terhadap lingkungan yang dipengaruhi oleh perbedaan individu dan proses (Luthans, 2011:278). Stres kerja dapat diartikan sebagai suatu proses psikologis yang dianggap tidak menyenangkan yang terjadi akibat adanya tekanan dari faktor eksternal yaitu lingkungan. Terjadinya stres diakibatkan dari adanya tekanan yang bersumber dari ketidaksesuaian antara seseorang dengan lingkungan kerjanya. Stres yang daialami oleh seorang karyawan akibat adanya sebuah tekanan yang dihadapinya akan berpengaruh terhadap pekerjaannya (Robbins dan Judge, 2013:629). Alat ukur stres kerja yaitu faktor stres dari luar organisasi (Extraorganizational Stressors), faktor stres dari dalam organisasi (Organizational Stressors), faktor stres dari kelompok (Group Stressors), dan faktor Stres dari Individu (Individual Stressors) (Luthans, 2011:280)

\section{Kinerja Karyawan}

Kinerja adalah hasil yang diperoleh oleh suatu organisasi baik organisasi tersebut bersifat profit oriented dan non profit oriented yang dihasilkan selama satu periode waktu (Fahmi, 2016:176). Kinerja adalah keluaran yang dihasilkan oleh fungsi-fungsi atau indikator-indikator suatu pekerjaan atau suatu profesi dalam waktu tertentu (Wirawan, 2012:5) Kinerja karyawan adalah sebuah hasil kerja secara kualitas dan kuantitas yang diperoleh seseorang karyawan dalam mengerjakan pekerjaan tugasnya dan sesuai atas tanggung jawab yang diberikan kepadanya (Mangkunegara, 2013:67). Alat ukur kinerja tersebut sudah terwakili oleh alat ukur yang telah dipaparkan yaitu kualitas (mutu), kuantitas (jumlah), waktu (jangka waktu), penekanan biaya, pengawasan dan hubungan antar karyawan (Kasmir, 2016:208)

\section{Kerangka Pemikiran}

Kerangka pemikiran yang digunakan di dalam penelitian ini merupakan adopsi model penelitian sebelumnya yang akan digambarkan pada Gambar 1 berikut.

\section{Gambar 1. Kerangka Pemikiran}

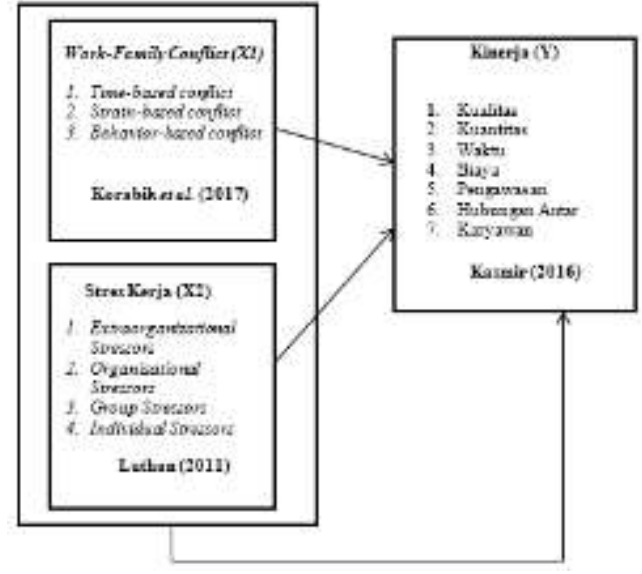

Feby Cahya Sapitri ${ }^{1)}$, Nidya Dudija ${ }^{2)}$ 


\section{Hipotesis}

Hipotesis 1

$\mathrm{HO}=$ Tidak terdapat pengaruh positif dan signifikan Work-Family Conflict terhadap Kinerja Karyawan.

H1 = Terdapat pengaruh positif dan signifikan Work-Family Conflict terhadap Kinerja Karyawan.

Hipotesis 2

$\mathrm{HO}=$ Tidak terdapat pengaruh positif dan signifikan Stres Kerja terhadap Kinerja Karyawan.

$\mathrm{H} 2$ = Terdapat pengaruh positif dan signifikan Stres Kerja terhadap Kinerja Karyawan.

Hipotesis 3

$\mathrm{H} 0=$ Tidak terdapat pengaruh positif dan signifikan Work-Family Conflict dan Stres Kerja terhadap Kinerja Karyawan.

H3 = Terdapat pengaruh positif dan signifikan Work-Family Conflict dan Stres Kerja terhadap Kinerja Karyawan.

\section{METODE PENELITIAN \\ Jenis Penelitian}

Metode yang digunakan pada penelitian ini adalah metode kuantitatif. Bedasarkan tujuan penelitian ini merupakanpenelitian desktriptif.Tipe penelitian yang digunakan adalah penelitian kausal. Dalam hal ini peneliti ingin mengetahui pengaruh work-family conflict terhadap kinerja karyawan RS Medika Dramaga. Unit analisis yang digunakan dalam penelitian ini adalah individu. Setting dalam penelitian ini adalah noncontrivied setting Berdasarkan waktu pelaksanaan, peneliti menggunakan jenis cross section.

\section{Tempat, Waktu dan Subjek Penelitian}

Penelitian dilakukan di RS Medika Dramaga Bogor yang terletak di Jalan Raya Dramaga No.KM. 7,3, RT.01/RW.06, Margajaya, Kecamatan Bogor Barat, Kota Bogor, Jawa Barat 16680. Dalam hal ini peneliti ingin mendeskripsikan work-family conflict dan stres kerja yang terjadi pada karyawan dan tingkat kinerja karyawan RS Medika Dramaga.Penelitian dimulai dari bulan Agustus 2019 sampai dengan Mei 2020.

\section{Teknik Pengumpulan Data}

Berdasarkan penelitian ini pengambilan sampel menggunakan teknik nonprobability sampling yaitu teknik pengambilan sampel yang tidak memberikan peluang ataupun kesempatan yang sama bagi setiap unsur anggota populasi untuk dipilih menjadi sampel dimana jumlah populasi sama dengan jumlah sampel dengan menggunakan metode sample jenuh yaitu teknik penentuan sampel apabila semua anggota populasi dijadikan sampel. yang akan menjadi populasi dalam penelitian ini adalah 121 tenaga kesehatan RS Medika dengan karakteristik sebagai berikut: (1) Karyawan wanita (2) Berstatus sudah menikah atau sudah pernah menikah. 


\section{Teknik Analisis Data}

Teknik analisis yang digunakan dalam penelitian ini adalah analisis deskriptif, uji asumsi klasik dengan menggunakan uji normalitas, uj multikolinearitas, dan uji heteroskedestisitas selain itu menggunakan analisis regresi berganda, koefisien determinasi serta ui hipotesis secara parsial (Uji T) dan secara simultan (Uji F). Teknik analisis data dalam proses pengujian setiap variabel menggunakan bantuan software SPSS Versi 25.

\section{HASIL PENELITIAN DAN PEMBAHASAN \\ Hasil Penelitian}

Berdasarkan usia responden pada peelitian ini dari 121 orang $\mathrm{r}$ karyawan wanita RS Medika Dramaga adalah mayoritas berusia antara >25 - 30 tahun yaitu sebayak 77 responden. Kemudian yang berusia antara $>30-35$ tahun yaitu sebanyak 20 responden, kemudian yang berusia antara 20-25 tahun sebanyak 18 responden kemudian yang berusia antara $>35$ - 40 Tahun yaitu sebanyak 4 responden dan yang paling sedikit responden yang berusia $>40$ tahun yaitu 2 responden.

Berdasarkan status pernikahan responden, dari 121 orang responden karyawan wanita RS Medika Dramaga adalah 117 orang berstatus sudah menikah dan 4 orang berstatus sudah pernah menikah.

Berdasarkan lama bekerja responden, dari 121 orang responden karyawan wanita RS Medika Dramaga mayoritas telah bekerja selama $1-3$ tahun yaitu sebanyak 61 responden. Kemudian yang sudah bekerja antara $>3-5$ tahun sebanyak 33 responden, kemudian yang bekerja $<1$ tahun sebanyak 14 responde, kemudian yang bekerja $>5-10$ tahun sebanyak 11 responden, dan yang paling sedikit responden yang telah bekerja $>10$ tahun yaitu 2 responden.

Berdasarkan jumlah anak responden dari 121 orang karyawan wanita RS Medika Dramaga. mayoritas memiliki anak antara $1-5$ anak yaitu sebanyak 88 responden,kemudian yang belum memiliki anak yaitu sebanyak 27 responden dan yang paling sedikit responden yang memiliki anak antara >5 -10 anak yaitu 6 responden.

Tabel 1. Koefisien Determinasi

Model Summary ${ }^{\mathrm{b}}$

\begin{tabular}{|c|c|c|c|c|}
\hline Model & R & R Square & $\begin{array}{c}\text { Adjusted R } \\
\text { Square }\end{array}$ & $\begin{array}{c}\text { Std. Error of } \\
\text { the Estimate }\end{array}$ \\
\hline 1 & $0.865^{\mathrm{a}}$ & 0.748 & 0.743 & 0.26852 \\
\hline
\end{tabular}

Sumber : Hasil Penelitian, diolah (2019)

a. Predictors: (Constant), Stres Kerja, Work Familiy Conflict

b. Dependent Variable: Kinerja

Uji Koefisien Determinasi telah dilakukan oleh penulis memperoleh angka (R) koefisien korelasi sebesar sebesar 0.748 artinya ada pengaruh antara variabel Work Family Conflict dan Stres Kerja terhadap Kinerja Karyawan Wanita sebesar $74.8 \%$ sedangkan sisanya $25.2 \%$ merupkan pengaruh variabel-variabel lain yang tidak peneliti libatkan dalam penelitian ini. 
Tabel 2. Koefisien Korelasi

Correlations

\begin{tabular}{|l|l|c|c|c|}
\hline \multicolumn{2}{|c|}{} & $\begin{array}{c}\text { Work Familiy } \\
\text { Conflict }\end{array}$ & $\begin{array}{c}\text { Stres } \\
\text { Kerja }\end{array}$ & Kinerja \\
\hline \multirow{2}{*}{$\begin{array}{l}\text { Work Fonflict } \\
\text { Comiliy }\end{array}$} & Pearson Correlation & 1 & $0.231^{*}$ & -0.637 \\
\cline { 2 - 5 } & Sig. (2-tailed) & & 0.011 & 0.000 \\
\cline { 2 - 5 } & $\mathrm{N}$ & 121 & 121 & 121 \\
\hline \multirow{3}{*}{ Stres Kerja } & Pearson Correlation & $0.231^{*}$ & 1 & -0.716 \\
\cline { 2 - 5 } & Sig. (2-tailed) & 0.011 & & 0.000 \\
\cline { 2 - 5 } & $\mathrm{N}$ & 121 & 121 & 121 \\
\hline
\end{tabular}

Sumber : Hasil Penelitian, diolah (2019)

*. Correlation is significant at the 0.05 level (2-tailed).

Uji koefisien korelasi menunjukan hasil perhitungan korelasi terlihat bahwa kekuatan hubungan antara work family conflit dan stres kerja dengan kinerja berada pada rentang 0,60 hingga 0,799. Artinya, terdapat hubungan yang kuat antara work family conflict dan stres kerja dengan kinerja karyawan wanita.

Tabel 3. Analisis Regresi Linear Beganda

\begin{tabular}{|c|c|c|c|c|c|c|c|}
\hline \multicolumn{8}{|c|}{ Coefficients $^{\mathrm{a}}$} \\
\hline \multirow{2}{*}{\multicolumn{2}{|c|}{ Model }} & \multicolumn{2}{|c|}{$\begin{array}{c}\text { Unstandardized } \\
\text { Coefficients }\end{array}$} & \multirow{2}{*}{$\begin{array}{c}\begin{array}{c}\text { Standardized } \\
\text { Coefficients }\end{array} \\
\text { Beta }\end{array}$} & \multirow[b]{2}{*}{$\mathbf{t}$} & \multirow[b]{2}{*}{ Sig. } & \multirow{2}{*}{$\begin{array}{c}\text { Correlations } \\
\text { Zero-order }\end{array}$} \\
\hline & & B & $\begin{array}{c}\text { Std. } \\
\text { Error }\end{array}$ & & & & \\
\hline \multirow[t]{3}{*}{1} & (Constant) & 6.213 & 0.168 & & 36.905 & 0.000 & \\
\hline & $\begin{array}{l}\text { Work Familiy } \\
\text { Conflict }\end{array}$ & -0.462 & 0.044 & -0.498 & -10.487 & 0.000 & -0.637 \\
\hline & Stres Kerja & -0.637 & 0.050 & -0.601 & -12.637 & 0.000 & -0.716 \\
\hline
\end{tabular}

Sumber : Hasil Penelitian, diolah (2019)

$$
\mathrm{Y}=6.213-0.462 \mathrm{X}_{1}-0.637 \mathrm{X}_{2}+e
$$

Uji regresi linear berganda yang telah dilakukan penulis memperoleh Koefisien regresi variabel $\mathrm{X}_{1}$ sebesar 0.462 mengandung arti untuk setiap pertambahan Work Family Conflict $\left(\mathrm{X}_{1}\right)$ sebesar satu satuan akan menyebabkan menurunnya Kinerja Karyawan Wanita (Y) sebesar 0.462 satuan. Dan Koefisien regresi untuk variabel bebas $\mathrm{X}_{2}$ bernilai negatif, menunjukkan adanya hubungan yang tidak searah antara Stres Kerja $\left(\mathrm{X}_{2}\right)$ dengan Kinerja Karyawan Wanita $(\mathrm{Y})$. Koefisien regresi variabel $\mathrm{X}_{2}$ sebesar 0.637 mengandung arti untuk setiap peningkatan Stres Kerja $\left(\mathrm{X}_{2}\right)$ sebesar satu satuan akan menyebabkan menurunnya Kinerja Karyawan Wanita (Y) sebesar 0.637 satuan. Koefisien regresi untuk variabel bebas $\mathrm{X}_{2}$ bernilai negatif, menunjukkan adanya hubungan yang tidak searah antara Stres Kerja $\left(\mathrm{X}_{2}\right)$ dengan Kinerja Karyawan Wanita (Y). Koefisien regresi variabel $\mathrm{X}_{2}$ sebesar 0.637 mengandung arti untuk setiap peningkatan Stres Kerja $\left(\mathrm{X}_{2}\right)$ sebesar satu satuan akan menyebabkan menurunnya Kinerja Karyawan Wanita (Y) sebesar 0.637 satuan. 
Tabel 4. Uji Work-Family Conflict terhadap Kinerja Karyawan Wanita Coefficients $^{\mathrm{a}}$

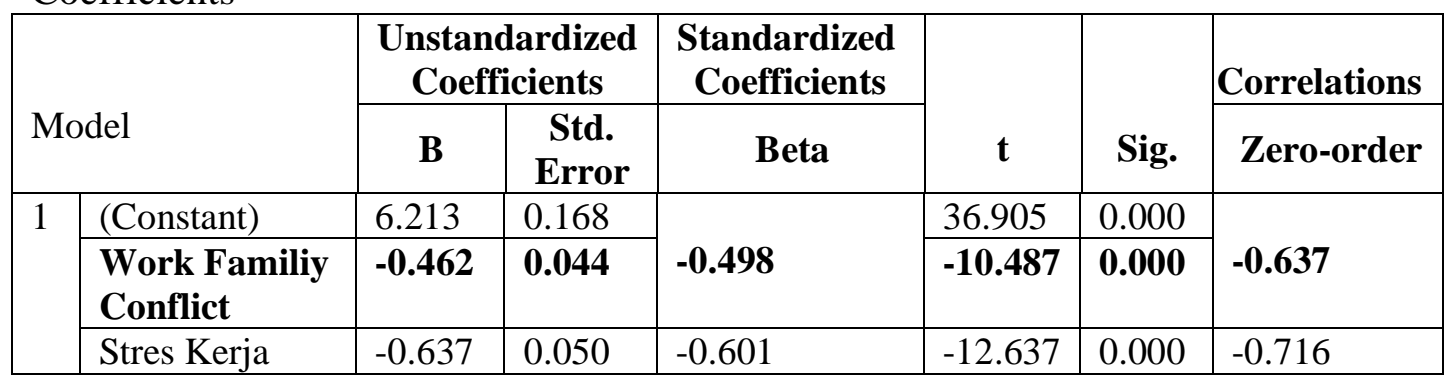

Sumber : Hasil Penelitian, diolah (2019)

a. Dependent Variable: Kinerja

Berdasarkan tabel di atas dapat diketahui bahwa arah hubungan Work Family Conflict dengan Kinerja Karyawan Wanita adalah negatif (perhatikan nilai koefisien Work Family Conflict pada kolom B), disana tertulis -0,462 artinya ketika ada peningkatan Work Family Conflict maka akan menurunkan Kinerja Karyawan Wanita. Coefficients $^{\mathrm{a}}$

\section{Tabel 5. Uji t Stres Kerja terhadap Kinerja Karyawan Wanita}

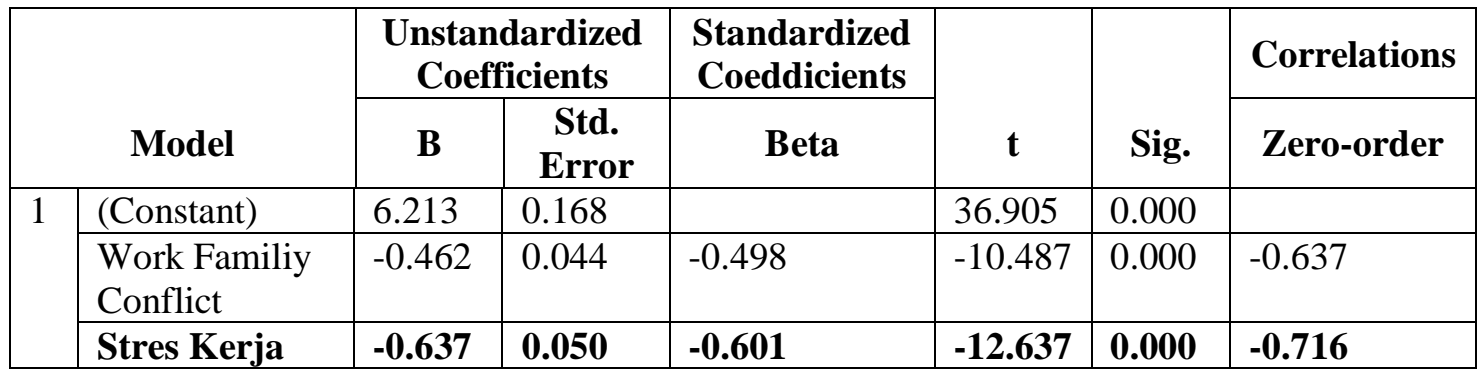

Sumber : Hasil Penelitian, diolah (2019)

a. Dependent Variable: Kinerja

Berdasarkan tabel di atas dapat diketahui bahwa arah hubungan Stres Kerja dengan Kinerja Karyawan Wanita adalah negatif (perhatikan nilai koefisien Stres Kerja pada kolom B), disana tertulis -0,637 artinya ketika ada peningkatan Stres Kerja maka akan menurunkan Kinerja Karyawan Wanita

Tabel 6. Uji F

\begin{tabular}{|l|l|c|c|c|c|c|}
\hline \multicolumn{7}{|l|}{ ANOVA $^{\text {a }}$} \\
\multicolumn{2}{|c|}{ Model } & $\begin{array}{c}\text { Sum of } \\
\text { Squares }\end{array}$ & df & $\begin{array}{c}\text { Mean } \\
\text { Square }\end{array}$ & F & Sig. \\
\hline \multirow{2}{*}{1} & Regression & 25.200 & 2 & 12.600 & 174.757 & $.000^{\text {b }}$ \\
\cline { 2 - 7 } & Residual & 8.508 & 118 & .072 & & \\
\cline { 2 - 7 } & Total & 33.708 & 120 & & & \\
\hline
\end{tabular}

Sumber : Hasil Penelitian, diolah (2019)

a. Dependent Variable: Kinerja

b. Predictors: (Constant), Stres Kerja, Work Familiy Conflict

Berdasarkan hasil perhitungan diketahui bahwa nilai F-hitung 174.757 dan kemudian nilai signifikansi (sig.0,000), jika dibandingkan antara nilai signifikansi (sig) dengan nilai alpha $(\alpha=0.05)$, maka nilai signifikansi lebih kecil dibandingkan nilai 
alpha, artinya variabel Work Family Conflict dan Stres Kerja memiliki pengaruh yang signifikan secara bersama-sama terhadap Kinerja Karyawan Wanita.

Berdasarkan uraian di atas dapat dibuat kesimpulan uji hipotesis yang dijabarkan sebagai berikut :

H1 : Hipotesis pertama dapat diterima karena terdapat pengaruh signifikan Work Family Conflict terhadap Kinerja Karyawan Wanita.

H2 : Hipotesis kedua dapat diterima karena terdapat pengaruh signifikan Stres Kerja terhadap Kinerja Karyawan Wanita

H3 : Hipotesis ketiga dapat diterima karena terdapat pengaruh signifikan antara Work Family Conflict dan Stres Kerja terhadap Kinerja Karyawan Wanita.

\section{KESIMPULAN DAN SARAN \\ Kesimpulan}

Berdasarkan hasil penelitian yang dikemukakan penulis bertujuan untuk mengetahui pengaruh work-family conflict terhadap kinerja karyawan di RS Medika Dramaga, untuk mengetahui pengaruh stres kerja terhadap kinerja karyawan di RS Medika Dramaga. Dan untuk mengetahui pengaruh work-family conflict dan stres kerja kinerja karyawan di RS Medika Dramaga. Maka, diperoleh kesimpulan sebagai berikut:

1. Terdapat pengaruh signifikan antara Work Family Conflict terhadap Kinerja Karyawan.

2. Terdapat pengaruh signifikan antara Stres Kerja terhadap Kinerja Karyawan.

3. Hasil yang diperoleh dari penelitian ini adalah terdapat pengaruh signifikan antara Work Family Conflict dan Stres Kerja terhadap Kinerja Karyawan Wanita. Artinya apabila work-family conflict meningkat dan stres kerja meningkat maka kinerja karyawan yang dihasilkan akan menurun.

\section{Saran}

1. Aspek Praktis

Saran dalam aspek praktis ini diharapkan menjadi sebuah masukan bagi perusahaan sebagai suatu pertimbangan dalam mengambil keputusan. Berikut adalah saran praktis yang dapat penulis sampaikan,

a. Karyawan RS Medika Dramaga hendaknya mempertimbangkan apabila terjadi peran ganda dalam kehidupan pekerjaan dan keluarga agar tidak terjadi konflik dikeduanya. Karyawan RS Medika Dramaga perlu bersikap secara professional dalam pekerjaannya terlebih manajemen waktu dan pembagian tanggung jawab atas dirinya dikeluarga atau dipekerjaan. Sehingga dalam menyelesaikan pekerjaannya tidak terganggu dengan konflik interpersonal maupun konflik di rumah dan karyawan dapat bekerja dengan tenang dan nyaman serta dapat memberikan kinerja yang maksimal bagi organisasi.

b. RS Medika Dramaga perlu bersikap tegas terhadap karyawannya dalam manajemen waktu. Hal tersebut bisa dilakukan dengan pengecekan kehadiran dan keterlambatan karyawan secara berkala dan evaluasi kinerja karyawan secara berkala agar karyawan menjadi disiplin karena mengingat pekerjaan dirumah sakit menyangkut kesejahteraan pasien. 
c. Agar para karyawan RS Medika Dramaga lebih termotivasi dan giat dalam bekerja, pentingnya memperhatikan dan meningkatkan gaji tambahan kepada karyawan RS Medika Dramaga Jasinga seperti upah lembur atau upah untuk pengambilan jadwal piket tambahan. Khusunya pada karyawan yang melaksanakan tugas tambahan baik dari tugas instansi pemerintahan kesehatan masyarakat maupun dari pihak rumah sakitnya sendiri.Selain itu kepala rumah sakit atau atasan memberikan penghargaan seperti memberikan pujian terhadap karyawan atau reward tambahan untuk karyawan yang telah melakukan pekerjaannya dengan baik. Hal tersebut dapat dilakukan dengan memeberikan bonus tambahan kepada karyawan untuk bekerja lebih baik lagi. Maka dari itu karyawan yang melakukan tugas tersebut merasa beban pekerjaan dan penghasilan yang diterima sudah sesuai dan akan berdampak kepada kinerja yang dilakukan karyawan menjadi lebih produktif.

d. Untuk menurunkan stres kerja dan meningkatkan kinerja karyawan pada waktu-waktu tertentu RS Medika Dramaga perlu mengadakan rekreasi karyawan bersama atau bahkan karyawan dapatmengajak keluarganya. Rekreasi tersebut bisa menjadi sarana bagi karyawan untuk menghilangkan penat dan jenuh atas pekerjaannya serta sarana bagi rumah sakit untuk mengenal keluarga karyawan dengan begitu bukan hanya meningkatkan loyalitas karyawan kepada rumah sakit namun juga dapat meningkatkan hubungan karyawan dengan keluarganya. Keluarga karyawanpun dapat mendukung keluarganya yang bekerja di RS Medika Dramaga sehingga kinerja karyawan dapat diberikan secara maksimal kepada RS Medika Dramaga.

2. Aspek Teoritis

Saran yang diberikan oleh peneliti dalam hasil penelitian ini untuk aspek teoritis diharapkan dapat memberikan kontribusi serta manfaat untuk mengembangkan penelitian dalam bidang ilmu khususnya sumberdaya manusia. Diharapkan untuk penelitian selanjutnya dapat meneliti lebih dari tiga variabel, karena pada penelitian ini hanya terfokus pada dua variabel independent dan dependent yaitu variabel work-family conflict, stress kerja dan kinerja karyawan. Sehingga diharapkan untuk peneliti selanjutnya dapat mengembangkan penelitian ini dengan menambah variabel yang terkait dengan work-family conflict, stres kerja dan kinerja karyawan. Selain itu, peneliti selanjutnya diharapkan mampu memberikan gambaran yang lebih luas dengan menggunakan metode yang tidak dipakai dalam penelitian ini seperti metode kualitatif. Tidak hanya itu, diharapkan pula untuk peneliti selanjutnya dapat meneliti instansi kesehatan yang lain seperti farmasi atau objek tempat penelitian lain di daerah lain atau kota lain. Karena penelitian ini hanya terfokus kepada instansi kesehatan rumah sakit di daerah Bogor. 


\section{DAFTAR PUSTAKA}

Badan Pusat Statistik 2010. Jumlah Angkatan Kerja. [Online] https://www.bps.go.id/statictable/2016/04/04/1904/penduduk-berumur-15-tahun[8 Januari 2020]

Fahmi, I. 2016. Pengantar Manajemen Sumber Daya Manusia. Jakarta: Mitra Wacana Media.

Handoko, H. 2014. Manajemen Personalia dan Sumber Daya Manusia (21 th ed.). Yogyakarta: BPFE- Yogyakarta.

Kasmir. 2016. Manajemen Sumber Daya Manusia, Teori dan Praktik (cetakan kedua). Jakarta: PT. Raja Grafindo Persada.

Korabik, K., Aycan, Z., \& Ayman R. 2017. The Work-Family Interface in Global Contex. Jakarta: Routledge.

Luthans, F. 2011. Organizational Behavior: an evidence-based approach. (12th ed.).New York: McGraw- Hill Irwin.

Mangkunegara, A. P. 2013. Manajemen Sumber Daya Manusia Perusahaan (11 th ed.). Bandung: PT Remaja Rosdakarya.

Retnaningrum, A. K., \& Al Musadieq, M. 2016. Pengaruh Work-Family Conflict Terhadap Kepuasan Kerja dan Kinerja (Studi pada perawat wanita RSUD Wonosari Yogyakarta). Jurnal Administrasi Bisnis, 36(1), 72- 81

Robbins, S. P., \& Judge, T. A. 2013. Organizational Behavior. (15th ed.). New Jersey: Pearson Education Inc.

Setiyanto, A.D. 2017. Desain Wanita Karier Menggapai Keluarga Sakinah. Yogyakarta: Depublish

Sugiyanto, E., Irawati, Z., dan Padmantyo, S. 2016. Konflik Pekerja Keluarga dan Pengaruhnya Terhadap Kinererja Pegawai (Studi Kasus rumah Sakit Berbasis Islam di Surakarta). IQTISHADIA, 9 (1) 91027.

Tjokro, C. I. 2015. Pengaruh Konflik Peran Ganda dan Stress Kerja terhadap Kinerja Perawat Rumah Sakit Umum Dr. M. Haulussy Ambon. ARTHAVIDYA, 17(1). $1-11$

Wirawan. 2012. Evaluasi Kinerja Sumber Daya Manusia. Jakarta: Salemba. 